\title{
Serial Dexamethasone Suppression Tests in Simultaneous Panic and Depressive Disorders
}

\author{
Leon Grunhaus, Pam Flegel, Roger F. Haskett, and John F. Greden
}

Recent work suggests that the simultaneous occurrence of major depressive disorder $(M D D)$ and panic disorder (PD) may be of relevance for clinical findings, therapeutic outcome, and prognosis. It is of interest to know whether or not this relevance extends to biological findings. We addressed this question through comparison of serial Dexamethasone Suppression Test (DST) results in patients who had either MDD alone or simultaneous MDD and $P D$. We were unable to describe differences between the groups.

\section{Introduction}

Recent communications have stressed the frequent association of panic disorder (PD) and major depressive disorder (MDD) (Leckman et al. 1983a,b; Breier et al. 1984; Bueno et al. 1984; Weisman et al. 1984; Grunhaus et al. 1984, 1985, 1986; Grunhaus and Birmaher 1985). It appears that when PD combines with MDD, a more severe disturbance may then be present; these patients may have (1) increased need for psychiatric treatments and hospitalizations, (2) poorer treatment outcome and prognosis, and (3) increased incidence of family psychopathology. It is then important to determine whether or not the combined condition of PD and MDD has biological characteristics that differentiate it from either disorder alone. The Dexamethasone Suppression Test (DST) has been extensively studied in MDD and also in PD or agoraphobia with panic attacks (Curtis et al. 1982; Liberman et al. 1983; Sheehan et al. 1983; Cottraux and Claustrat 1984; Avery et al. 1985; Coryell et al. 1985; Petterson et al. 1985; Roy-Byme and Uhde 1985). Approximately $50 \%$ of MDD patients and less than $20 \%$ of PD patients will show DST nonsuppression. Thus, it is of interest to see whether or not the presence of PD in MDD patients has an impact on the suppressibility of the DST when compared to patients with MDD alone. Grunhaus et al. (1984, 1986) and Bueno et al. (1984) have reported on the DST results of patients with MDD and simultaneous PD compared to patients with MDD alone. They found similar rates of nonsuppression in both groups of depressed patients. Grunhaus et al. and Bueno et al. included both inpatients and outpatients in their studies and based their conclusions on a single diagnostic test. To clarify this point further, we studied an inpatient population with simultaneous PD and MDD and compared them to an age- and severity-matched group with MDD alone, using multiple timepoints for the

From the Clinical Studies Unit, University of Michigan Psychiatric Hospitals, Ann Arbor, MI.

Supported in part by NIMH Grant 1-RO1-MH40216-01 and the Psychiatry Department of the University of Michigan.

Address reprint requests to Dr. Leon Grunhaus, 1500 East Medical Drive, University of Michigan Hospital. Department of Psychiatry, Clinical Studies Unit, D9702 Box 0118 Ann Arbor, MI 48109-0118

Received July 14, 1986: revised August 25, 1986. 
DST. The added anxiety diagnosis had no impact on the suppressibility of the DST of the depressed patients. Some interesting clinical features of the combined syndrome were found.

\section{Methods}

This study was conducted at the Clinical Studies Unit (CSU) for Affective Disorders, which is a 12-bed inpatient unit with an adjacent outpatient program specializing in research and treatment of affective disorders. We included only inpatients between the ages of 20 and 65 years. Our standard CSU evaluation consisted of a 14-day drug-free period for the majority of patients, several clinical interviews, a structured diagnostic interview [Schedule for Affective Disorders and Schizophrenia (SADS) and SADS-Lifetime Version (SADS-L)], a thorough medical evaluation, and a diagnostic family interview. Comprehensive diagnoses were formulated based on Research Diagnostic Criteria (RDC) (Spitzer et al. 1975).

The study was designed to compare two groups of patients: those with simultaneous PD and MDD (simultaneous group) and those with only MDD (depressed group). The diagnosis of PD was based on the ratings on panic attacks in the current episode of illness obtained from the SADS interview. For inclusion into the simultaneous group, our first step was to determine if subjects met RDC criteria for MDD. Our next step was to determine if subjects met RDC criteria for PD: if so, we diagnosed both conditions regardless of whether subjects had MDD (this is a modification of written RDC criteria for MDD). None of the patients with MDD alone (depressed group) met diagnostic criteria for PD or agoraphobia, either for the current episode of illness or in their life history (as reported in the SADS-L).

The patients in the simultaneous group were matched with patients from the depressed group for the following variables: (1) age within 5 years (2) adjusted Hamilton Rating Scale for Depression (A-HRSD) within 3 points (the A-HRSD was obtained by subtracting the psychic and somatic anxiety ratings), and (3) diagnosis of MDD endogenous subtype and nonendogenous subtype according to RDC. Other inclusion criteria for both groups were: (1) Hamilton Rating Scale for Depression (HRSD) (Hamilton 1960) of 12 or more (2) no technical exclusion criteria known to invalidate biological correlates (Carroll et al. 1981), (3) no other illness that could account for the panic attacks, (4) absence of pregnancy, and (5) informed consent for participation in research. Investigators and clinical raters were blind to research variables.

The DST was performed using the standardized version of Carroll et al. (1981), giving $1 \mathrm{mg}$ of dexamethasone at 11:00 PM on day 1 and measuring blood samples at 4:00 and 11:00 PM on day 2. We matched only those who had at least three DSTs during their hospital stay. DSTs were considered nonsuppressive if either of the values of day 2 were above $5 \mu \mathrm{g} / \mathrm{dl}$. Patients were considered to be nonsuppressors if they had any of the pretreatment DSTs above the cut-off of $5 \mu \mathrm{g} / \mathrm{dl}$. Plasma cortisol was assayed using a competitive protein-binding assay (Murphy 1967), which has been standardized for the lower ranges of plasma cortisol. The patients with simultaneous MDD and PD reported here are a subsample of those with longitudinal data of a previously reported study (Grunhaus et al. 1986).

Patients were compared on the following variables: (1) HRSD and age-matching criteria; (2) baseline, midtreatment, and predischarge post-DST plasma cortisol using a cutoff point of 5 and absolute and log-transformed plasma cortisol values; (3) SADS and 
SADS-L variables of social function, outcome of previous episode, number of previous episodes of depression, level of function in past 5 years, and Global Assessment Scale (GAS); and (4) a number of clinical variables and family history of affective disorders. Dichotomous variables were analyzed with the chi-square test, matched samples with a paired $t$-test, and unpaired clinical variables with a two-sample Student's $t$-test.

Treatment was prescribed by the attending psychiatrist as clinically indicated. Response to treatment was assessed with our standard method: (1) good response-those having a drop in their HRSD score of $50 \%$ or more and having a final HRSD of 10 or less; (2) partial response-whenever the HRSD dropped $50 \%$ or more but remained above 10 ; and (3) poor response-whenever responses 1 or 2 were not met. Treatment regimens were comparable between the groups. Treatment outcome variables will be described in detail elsewhere, as part of a larger sample of treated patients with MDD-PD (Grunhaus et al., in preparation).

\section{Results}

Sixteen inpatients with MDD and PD were matched with others with MDD alone. All of the patients were primary MDDs. The matching variables were similar for both groups and are presented in Table 1. As a cross-validation of the adequate matching of the severity of illness, the GAS was also similar in both groups (Table 1). Indicators of hypothalamus-pituitary-adrenal (HPA) function values (highest postdexamethasone plasma cortisol, log-transformed plasma cortisol, and number of nonsuppressors) in the two groups were not significantly different at baseline, midtreatment, or discharge. The process of normalization of the DST with treatment can be observed in Figure 1; the profile analysis at three time points-baseline, midtreatment, and discharge--did not reveal significant differences between the groups.

Table 1. Clinical and DST Variables

\begin{tabular}{|c|c|c|c|c|c|c|c|}
\hline & $n$ & MDD-PD ${ }^{a}$ & $\mathrm{MDD}^{b}$ & $\mathrm{SD}$ & Paired- $t$ & Two-sample $t$ & $x^{2}$ \\
\hline Age & 16 & 40.5 & 41.9 & 2.9 & $-2.0 \mathrm{NS}$ & & \\
\hline HRSD & 16 & 21.7 & 19.6 & 7.3 & $1.1 \mathrm{NS}$ & & \\
\hline A-HRSD & 16 & 16.7 & 16.6 & 5.7 & $-0.7 \mathrm{NS}$ & & \\
\hline GAS & 16 & 49.4 & 48.4 & 17.7 & $0.2 \mathrm{NS}$ & & \\
\hline D-HRSD & 16 & 9.0 & 6.5 & 7.5 & $0.8 \mathrm{NS}$ & & \\
\hline DA-HRSD ${ }^{c}$ & 16 & 7.0 & 4.9 & 6.5 & $0.9 \mathrm{NS}$ & & \\
\hline B-Cortisol ${ }^{d}$ & 16 & $5.1 \pm 5.1$ & $5.9 \pm 7$ & & & $0.2 \mathrm{NS}$ & \\
\hline M-Cortisol ${ }^{d}$ & 16 & $4.2 \pm 1.3$ & $3.8 \pm 0.9$ & & & $0.3 \mathrm{NS}$ & \\
\hline D-Cortisol ${ }^{d}$ & 16 & $4.1 \pm 1.8$ & $2.6 \pm 0.7$ & & & $0.8 \mathrm{NS}$ & \\
\hline Log-DST (base) & 16 & $1.2 \pm 0.9$ & $1.1 \pm 1.1$ & & & $1.7 \mathrm{NS}$ & \\
\hline \multicolumn{8}{|c|}{ Percent nonsuppression } \\
\hline Baseline & 16 & $9 / 16$ & $8 / 16$ & & & & NS \\
\hline Discharge & 16 & $3 / 16$ & $3 / 16$ & & & & NS \\
\hline Previous MDD $^{e}$ & $13 / 15$ & $2.8 \pm 2.9$ & $1.7 \pm 1.9$ & & $1.2 \mathrm{NS}$ & & \\
\hline \multicolumn{8}{|l|}{ Hospitalizations } \\
\hline for $\mathrm{MDD}^{e}$ & $12 / 13$ & $3.6 \pm 2.9$ & $1.7 \pm 1.9$ & & 1.50 .06 & & \\
\hline
\end{tabular}

${ }^{a} \mathrm{MDD}$ with panic disorder group.

${ }^{b}$ MDD only group.

'D-HRSD, discharge HRSD. DA-HRSD, discharge A-HRSD

${ }^{d} \mathrm{~B}$, baseline; $\mathrm{M}$, midtreatment; $\mathrm{D}$, discharge values.

'Numerator MDD-PD group. denominator MDD only group. 


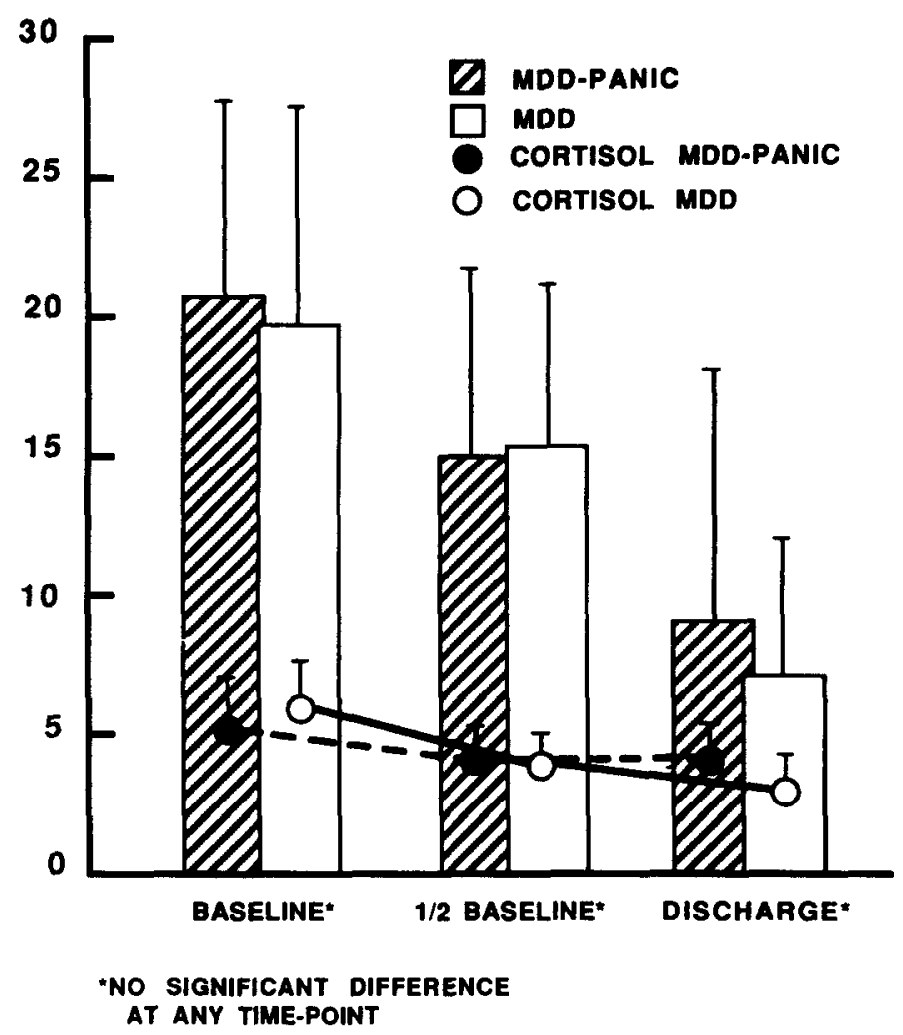

Figure 1. Baseline, midtreatment, and discharge values for the maximal postdexamethasone plasma cortisol values, HRSD, and A-HRSD in patients with MDD-PD or MDD only. Significance measured by paired Student's $t$-tests.

The clinical variables were strikingly similar. The SADS ratings for outcome from previous episodes, highest level of function in past 5 years, social function, and number of outpatient treatments did not differentiate between the groups. A number of longitudinal variables (age at first episode of depression, previous suicide attempts, family history for affective disorders, and length of current episode) were similar in both groups. Interestingly, previous hospitalizations for depression and number of previous episodes of endogenous depression were more frequent, but not significantly different, in those with MDD-PD. The individual HRSD items, including those of psychic and somatic anxiety, did not differentiate between the groups; thus, the patients with PD and MDD were not more severely anxious. The correlations between total HRSD and A-HRSD with baseline postuexamethasone maximal cortisol values were highly significant in both groups (MDDPD: $r=0.46, p=0.00001 ; \mathrm{MDD}: r=0.43, p=0.00001$ ).

\section{Discussion}

Our findings confirm previous reports by Grunhaus et al. (1985) and Bueno et al. (1984) that HPA function is not different in MDD and MDD-PD patients. In our population of MDD and PD patients, the rate of nonsuppression (56\%) was similar to that of the MDD 
only patients $(50 \%)$. This lack of differentiation persisted throughout the hospitalization and the process of normalization of the DST during treatment. The rate of nonsuppression at discharge was similar in both groups: approximately $20 \%$.

From a clinical perspective, both groups appeared to be very similar. The differences observed were with regard to the number of hospitalizations and previous episodes of MDD. Patients with PD and MDD had been hospitalized more often and also had a history of more frequent episodes of MDD. Even though these results did not reach statistical significance, probably due to the small sample, they may be an indication of a more severe course of illness, which is in line with other recent reports (Breier et al. 1984; Weissman et al. 1984; Leckman et al. 1983a). Further indication of the possibly more severe quality of the combined condition comes from the difficulties these patients have remaining drug-free during our customary diagnostic and observation period. Twentyfive percent of the PD and MDD group could not reach the 2-week drug-free period, whereas all of the MDD only patients were able to do so.

It appears then, that the hypothalamic-pituitary-adrenal (HPA) axis dysfunction, as measured through negative feedback loops with the DST, is very similar in MDD only patients and those with the simultaneous syndrome. Together with the findings of low nonsuppression rates in PD only patients, it is possible to suggest that the underlying physiopathology of PD does not have an impact on the HPA axis function as measured with the DST. These findings support the specificity of the DST with regard to anxiety conditions and, particularly, PD.

Increased levcls of adrenergic secretions (epinephrine, norepinephrine, MHPG, and DOPEG) in MDD patients who also have DST nonsuppression have been described by some authors (Barnes et al. 1983; Jimmerson et al. 1983), but not by others (Loo et al. 1985). Similarly, increased adrenergic tone has been proposed as central to anxiety conditions (Redmond and Huang 1979), and some authors have found elevated adrenergic products in panic conditions (Ko et al. 1983; Cameron et al. 1984). It is then possible to suggest that in the presence of both psychopathologies, MDD and PA, the rate of nonsuppression would be higher. As evidenced by our results, we found no difference in the rates of DST nonsuppression in our group of patients.

Even though it appears that the DST results are similar in patients with either MDD or simultaneous MDD and PA, both at pretreatment and discharge time points, it is yet unclear whether or not any differences may be identified in prognosis. In follow-up studies, it would be of interest to test the hypothesis that the simultaneous syndrome of MDD and PA, and by inference to DST nonsuppression associated to a hyperadrenergic state, will have a worse outcome than MDD alone. As mentioned in our introduction, some outcome studies (Van Valkenburg et al. 1984) already lend support to the clinical aspects of this hypothesis. We are currently engaged in a study collecting data to test the biological aspects of it.

\section{References}

Avery DH, Osgood TB, Ishiki DM, Wilson LG, Kenny M, Dunner DL (1985): The DST in psychiatric outpatients with generalized anxiety disorder, panic disorder or primary affective disorder. Am J Psychiatry 142:844-848.

Barnes RF, Veith RC, Borson S, Verhey J, Raskind MA, Halter JB (1983): High levels of plasma catecholamines in dexamethasone resistant depressed patients. Am J Psychiatry 140:1623-1625.

Breier A, Charney DS, Heninger GR (1984): Major depression in patients with agoraphobia and panic disorder. Arch Gen Psychiatry 41:1129-1135. 
Bueno JA, Sabanes F, Gascon J, Gasto C, Salamero M (1984): Dexamethasone Suppression Test in patients with panic disorder and secondary depression. Arch Gen Psychiatry 41:723-724.

Cameron OG. Smith CHB, Hollingsworth PJ. Nesse RM, Curtis GC (1984): Platelet alpha adrenergic receptor binding and plasma catecholamines. Arch Gen Psychiatry 41:1144-1148.

Carroll BJ, Feinberg M, Greden JF, Tarika J, Albala AA, Haskett RF, James NM, Kronfol Z, Lohr N, Steinger M, de Vigne JP, Young E (1981): A specific diagnostic test for the diagnosis of melancholia: Standardization, validation and clinical utility. Arch Gen Psychiatry 38:15-22.

Coryell W, Noyes JR, Clancy J, Crowe R, Chaudhry D (1985): Abnormal escape from dexamethasone suppression in agoraphobia with panic attacks. Psychiatry Res 15:301-311.

Cottraux J, Claustrat B (1984): Le test a la dexamethasone dans l'agoraphobie aveq attacks de panique. Encephale 10:267-272.

Curtis GC, Cameron OG, Nesse RM (1982): The Dexamethasone Suppression Test in panic disorder and agoraphobia. Am J Psychiatry 139:1043-1046.

Grunhaus L, Birmaher B (1985): The clinical spectrum of panic attacks. J Clin Psychopharmacol 5:93-99.

Grunhaus L, Rabin D, Greden JF, Feinberg M, Hermann R (1984): Simultaneous panic and depressive disorder: Neuroendocrine and sleep EEG correlates. Society for Biological Psychiatry Meeting, Los Angeles, California.

Grunhaus L, Haskett R, Greden JF, Tiongco D (1985): Serial DSTs in patients with MDD and MDD + panic disorder. World Psychiatric Association Regional Symposium, Athens, October.

Grunhaus L, Rabin D, Greden JF (1986a): Simultaneous panic and depressive disorders: Response to antidepressant treatments. $J$ Clin Psychiatry 47:4-7.

Grunhaus L, Rabin D, Harel Y, Greden JF, Feinberg M, Hermann R (1986b): Simultaneous panic and depressive disorder: Clinical and sleep EEG correlates. Psychiatry Res 17:251-259.

Hamilton M (1960): A rating scale for depression. J Neurol Neurosurg Psychiatry 23:56-62.

Jimmerson DC, Insel TR, Reus VI, Kopin IJ (1983): Increased plasma MHPG in dexamethasone resistant depressed patients. Arch Gen Psychiatry 40:173-176.

Ko GN, Elsworth JD, Roth RH, Rifkin BG, Leigh H, Redmond DE Jr (1983): Panic induced elevations of plasma MHPG levels in phobic-anxious patients. Arch Gen Psychiatry 40:425-430.

Leckman JF, Merikangas KR, Pauls DL, Prusoff BA, Weissman MM (1983a): Anxiety disorders and depression. Contradictions between family study data and DSM-III conventions. Am J Psychiatry 140:880-882.

Leckman JF, Weissman MM, Merikangas KR, Pauls DL, Prusoff BA (1983b): Panic disorder and major depression. Arch Gen Psychiatry 40:1055-1060.

Lieberman JAS, Grenner R, Coccaro E, Borenstein M, Kane JM (1983): Dexamethasone Suppression Tests in patients with panic disorder. Am J Psychiatry 140:917-919.

Loo II, Benkelfast B, Dennis T, Poirier MF, Vanelle JM, Olie JP, Susini de Luca H (1985): Hypothesis of a deficiency of central noradrenergic input in DST nonsuppressor depressed patients. A clinical study with determination of DST and plasma dopeg: Negative results. In Kemali D, Racagni G (eds), Chronic Treatments in Neuropsychiatry. New York: Raven Press.

Murphy BEP (1967): Some studies of the protein binding of steroids and their application in body fluids by competitive protein binding radioassay. J Clin Endocrinol Metab 27:973-990.

Petterson GA, Ballenger JC, Cox DP, Hucek A, Lydiard RC, Laraia MT, Trockman C (1985): The Dexamethasone Suppression Test in agoraphobia. J Clin Psychopharmacol 5:100-102.

Redmond DE Jr, Huang YH (1979): New evidence for a locus coeruleus norepinephrine connection with anxiety. Life Sci 25:2149-2162.

Roy-Byme PP, Uhde TW (1985): Panic disorder and major depression: Biological relationships. Psychopharmacol Bull 21:551-554.

Sheehan DV, Claycomb JB, Surman OS, Baer L, Colleman J, Gelles L (1983): Panic attacks and the Dexamethasone Suppression Test. Am J Psychiatry 140:1063-1064. 
Spitzer RL, Endicott J, Robins E (1975): Research Diagnostic Criteria. New York: New York Psychiatric Institute Biometrics Research.

Van Valkenburg Ch, Akiskall HS, Puzantian B, Rosethal T (1984): Anxious depressions. $J$ Affect Dis 6:67-82.

Weissman MM, Leckman JF, Merikangas KR, Gammon GD, Prusoff BA (1984): Depression and anxiety disorders in parents and children. Arch Gen Psychiatry 41:845-852. 